Luque, M. O. \& Soler, S. (2019). Training audio describers for art museums. Linguistica Antverpiensia, New Series: Themes in Translation Studies, 18, 166-181.

\title{
Training audio describers for art museums
}

\author{
M. Olalla Luque Colmenero \\ Universidad de Granada, Spain \\ molc@ugr.es \\ 0000-0003-1266-5467 \\ Silvia Soler Gallego \\ Colorado State University, United States \\ ssoler@colostate.edu \\ 0000-0003-1949-711X
}

\begin{abstract}
Audio description (AD) for art museums and exhibitions is a growing professional field. This article investigates the profiles of audio describers for art museums that exist today and presents a curriculum proposal for one of these profiles, namely the graduate in Translation Studies. This proposal consists of the incorporation of an internship in art museum AD into the Translation Studies curriculum. More specifically, this article describes the internship offered by the Kaleidoscope non-profit association, based in Granada, to graduates in Translation. Our proposal is discussed in relation to Kiraly's $(2000,2012)$ social constructivist and holisticexperiential approaches to translator education and recent studies that advocate more internship opportunities for Translation graduates to help their meta-competence emerge (Kiraly \& Hofmann, 2016) and to foster their employability (Schnell \& Rodríguez, 2017).
\end{abstract}

Keywords: Audio describer profile, art museum, internship, situated learning

\section{Introduction}

Accessibility is an increasingly important goal for museums and especially for art museums. During the past 15 years, more and more museums have become aware of their responsibility for designing environments and experiences intended for a variety of visitors, including blind and partially sighted (BPS) people. For this purpose, they have started to collaborate with associations of blind people and companies that specialize in tactile graphics, mobile guides and translation that can help them achieve this goal. These companies have seen an opportunity in this field and have started to offer services intended for BPS visitors of art museums. In the academic context, some researchers of audio description (AD) have incorporated this intersemiotic modality into the higher education (HE) curriculum and have applied their research to the development of accessibility projects for museums through freelance work, funded research projects, and non-profit organizations. As a result, it is fair to say that today, AD for art museums is a growing professional practice. Nevertheless, there is 
Luque, M. O. \& Soler, S. (2019). Training audio describers for art museums. Linguistica Antverpiensia, New Series: Themes in Translation Studies, 18, 166-181.

still a lack of research on the profile of the "audio describer for art museums" which could develop and improve accessibility programmes and curriculum design in this area.

Against this background, an internship in AD for art museums was first offered in 2016 by Kaleidoscope, a non-profit association created by the authors to improve accessibility to culture. To this end, we offer training and consulting services, accessibility solutions for museums and heritage sites, and films for BPS people. One of these solutions is the design and implementation of guided tours to art museums and exhibitions with $A D$ and tactile images, followed by an art creation workshop.

The aim of this article is to investigate the existing qualification and competence profile of audio describers for art museums and to present a curriculum proposal for one of these profiles, namely the graduate in Translation Studies. First, we describe the educational and professional background of audio describers based on the results of a context-oriented descriptive study we carried out. This type of research does not focus on the product of a translation process or the process itself but on the situation in which it takes place (Saldanha \& O'Brien, 2013, p. 17). Next, the European Graduate Placement Scheme (Kiraly \& Hofmann, 2015) and "employability" (Schnell \& Rodríguez, 2017) are discussed in connection with the Translation Studies graduate profile. Finally, we present our proposal for an internship for this profile and its connection with Kiraly's $(2000,2012)$ holistic-experiential approach to translator education.

\section{A survey of the "audio describer for art museums" profile}

In the field of media AD, Orero (2005) states that:

In most European countries (such as Belgium, France, Germany, and Spain), and because audio description (AD) is only done internally at [a] social level, people who do AD are generally volunteers. Some describers (this term will be used hereafter as a synonym of "audio describer") have received training, but some of them perform $A D$ because they have relatives with impairments or because they have an interest in amateur theatre (pp. 8-9).

A recent study that surveyed audio describers for TV, cinema, the performing arts and other live events, and museums in Europe concluded that most of them had professional experience in audiovisual translation (22\%), teaching (10\%), acting (10\%), radio or TV $(10 \%)$, other types of translation (8\%), journalism (6\%) or writing (3\%). This study determined that the educational background and AD training among audio describers are also varied. Most candidates had completed studies in languages and linguistics, literature or translation and, to a lesser extent, in film and TV studies, journalism and media studies, theatre studies, acting and arts and/or museum studies. Only 32 per cent of the participants were trained in $A D$ (ADLAB PRO, 2017, p. 47). Among the competences for audio describers indicated in the results of the ADLAB PRO project $(2017$, p. 18), those that we consider as being relevant to live $A D$ in art museums are the following:

- Select significant visual information

- $A D$ script writing and textual editing

- AD voicing

- AD history, status and applicable scenarios 
Luque, M. O. \& Soler, S. (2019). Training audio describers for art museums. Linguistica Antverpiensia, New Series: Themes in Translation Studies, 18, 166-181.

- AD principles, guidelines and standards

- Work in a team with blind patrons.

These should be developed along with a knowledge of art history (Díaz Cintas, 2007) and, more specifically, a knowledge of the works selected for each tour.

To draw a more detailed picture of the profile of the audio describer for art museums, we decided to study museums in Spain, France, the United Kingdom and the United States that offer an audio descriptive guide (ADG) or an audio descriptive guided tour (ADGT) for their BPS visitors. These countries were chosen for being among those where museum accessibility has developed considerably in the past decade and because we had the linguistic proficiency needed to carry out the study. The aim of this study is to offer descriptive data on some of the existing profiles in this particular field. A search of the web and related publications allowed us to identify 33 museums and exhibitions that offer AD resources: 12 in Spain, seven in France, four in the United Kingdom and ten in the United States (Table 1). Among them, 14 offer ADG, ten offer ADGTs and nine offer both ADG and ADGTs. Data on the audio describers' profile were collected from the museum websites and other relevant publications, as well as through semi-structured interviews and an online questionnaire with open-ended questions. Qualitative data-analysis software (Atlast.ti) was used to categorize and analyse the information provided by the participants. This context-oriented study is part of a larger project that includes a corpus-based study of $A D$ in art museums (see Soler Gallego \& Luque Colmenero, 2018, for a detailed explanation of the project and the method followed in the contextual study).

Table 1 Museums and exhibitions in the study.

\begin{tabular}{|c|c|}
\hline AD resource & Museum and exhibition \\
\hline \multirow{14}{*}{ ADG } & Guggenheim Museum Bilbao, Spain \\
\hline & Museo de Bellas Artes de Bilbao, Spain \\
\hline & $\begin{array}{l}\text { Colchester and Ipswich Museums, UK: Seventeen in } \\
\text { Print }\end{array}$ \\
\hline & Grand Palais, France: Velázquez, Icones americaines \\
\hline & Royal Academy of Arts, UK: Watteau: The Drawings \\
\hline & Midlands Art Centre, UK: Vanley Burke \\
\hline & Musée de l'Orangerie, France \\
\hline & Musée du Louvre, France \\
\hline & Museo Carmen Thyssen Málaga, Spain \\
\hline & Museo Julio Romero de Torres, Spain \\
\hline & Museo Lázaro Galdiano, Spain \\
\hline & Museo Nacional del Prado, Spain \\
\hline & $\begin{array}{l}\text { New York Historical Society: The Armory Show at 100: } \\
\text { Modern Art and Revolution, USA }\end{array}$ \\
\hline & The Andy Warhol Museum, USA \\
\hline \multirow{4}{*}{ ADG and ADGT } & Museum of Fine Arts, Boston \\
\hline & Museo Sorolla, Spain \\
\hline & Musée d'Art Moderne de la Ville de Paris, France \\
\hline & Musée d'Orsay, France \\
\hline
\end{tabular}


Luque, M. O. \& Soler, S. (2019). Training audio describers for art museums. Linguistica Antverpiensia, New Series: Themes in Translation Studies, 18, 166-181.

\begin{tabular}{|l|l|}
\hline \multirow{5}{*}{} & Museo Nacional Centro de Arte Reina Sofía, Spain \\
\cline { 2 - 3 } & Solomon R. Guggenheim Museum, USA \\
\cline { 2 - 3 } & Museum of Modern Art, New York \\
\hline & Rubin Museum of Art, USA \\
\cline { 2 - 3 } & Tate Modern, UK \\
\hline & Brooklyn Museum, USA \\
\hline & La Pedrera (temporary exhibitions), Spain \\
\hline & Musée Cernuschi, Spain \\
\hline & Musée d'Art Contemporain du Val-de-Marne, France \\
\hline & Museo CajaGranada, Spain \\
\hline & Metropolitan Museum of Art of New York City, USA \\
\hline & $\begin{array}{l}\text { Patronato de la Alhambra (temporary exhibitions), } \\
\text { Spain }\end{array}$ \\
\hline & Petit Palais, France \\
\hline & Philadelphia Museum of Art, USA \\
\hline & Whitney Museum of American Art, USA \\
\hline
\end{tabular}

At five of the 19 museums offering ADGT, the guides responsible for the tours for BPS people work permanently for the museum. They have completed higher-education studies in Visual Arts, Art History, Art Education or Museum Studies, or a combination of them, and have experience as educators or museum guides. In addition to their education, at three of these five museums the audio describers were trained in accessibility and $A D$ by a non-profit organization, company or freelancer specializing in this field, such as ONCE (Organización Nacional de Ciegos de España, National Organization of the Blind in Spain), VocalEyes, and Art Beyond Sight. At two museums in the United States, volunteer guides are responsible for the audio descriptive guided tours after receiving training in accessibility and AD. In one case, volunteer guides are trained by the museum staff, who in turn are self-taught. In the other, they are trained by a company that specializes in museum accessibility for BPS people. At one Spanish museum, a guide from the museum designs and leads the tours along with a professional journalist and a filmmaker who is blind.

The audio describers at four French museums and five museums in the United States offering ADGT are freelance museum guides with an educational and professional background in art history and art museums. At all these museums except one, the audio describers were trained in accessibility and/or AD by a company that specializes in tactile graphics (Tactile Studio) or by an organization that specializes in accessible communication for BPS people (Art Beyond Sight). In addition, at one Spanish museum, the audio describer is the creator of an organization specializing in accessible communication. She has completed higher-education studies in Journalism and Translation and is a certified official guide for museums and heritage sites. At three other Spanish museums, the tours are given by the authors of this article, who are founding members of another non-profit organization and have completed both bachelor's and master's degrees in Translation Studies, including an MA course in film AD and a PhD in museum AD. Finally, at one French museum, the person guiding the tours is a writer and she is blind.

Regarding the 23 museums offering ADG, at six of them the audio descriptive guide was created by educators or accessibility coordinators who work permanently for the museum. 
Luque, M. O. \& Soler, S. (2019). Training audio describers for art museums. Linguistica Antverpiensia, New Series: Themes in Translation Studies, 18, 166-181.

These audio describers have an educational background in Visual Arts or Art History. One of them was trained in $A D$ by an organization of blind people (ONCE), two more by an organization specializing in accessible communication (Art Beyond Sight), and a fourth by a freelance expert in accessibility and $A D$ who offers training to museums. The museum staff at one museum in Spain collaborated with an audio describer who is blind and works for an organization of blind people.

The remaining 17 museums of the 23 that offer ADG hired companies that specialize in tactile graphics (Estudios Durero, Tactile Studio); companies dedicated to the creation of mobile guides for museums (Guías Virtuales Accesibles para Museos or GVAM, Acoustiguide, Antenna International); organizations of blind people (ONCE); organizations specializing in accessible communication (Rouge Vivier, VocalEyes); or a freelance audio describer to create the ADs. In Spain, one company collaborated with an organization of blind people to create the guides for three museums, and for a later project they hired an audio describer with an educational and professional background in translation. In the United Kingdom, the audio describer who created the guides for two museums works for an organization that specializes in accessible communication, has completed higher-education degrees in Social Anthropology and Psychology and was trained by an audio describer. Three other audio describers in this group work for the American or British branch of one of two international mobile guide companies (Acoustiguide and Antenna International) and were trained by the company staff. Among them, one has a university degree in Foreign Languages, while the other two have completed degrees in Art History. Of the latter two, one also completed degrees in Creative Writing, Comparative Literature and Foreign Languages, while the other has experience as a filmmaker, radio producer and journalist. One American museum hired a freelance audio describer to create the guides of several temporary exhibitions. This professional has experience as a radio presenter and a sound producer, and was trained by and collaborated for a number of years with an organization that specializes in accessible communication (Art Beyond Sight). Finally, one French museum hired a company that specializes in tactile graphics (Tactile Studio) and employs an in-house audio describer with a background in cultural mediation.

Two Spanish museums hired a company specializing in tactile graphics (Estudios Durero) that employs two in-house BPS audio describers. At three French museums, the audio describer is blind and holds a position in an organization of blind people, has university degrees in Anthropology and Accessibility Technologies and collaborates with an organization that specializes in accessible communication (Rouge Vivier). Another French museum hired a blind writer, who also guides tours at different museums in the Paris area, to create the ADs for their guide. These BPS audio describers collaborate with sighted assistants and the museum curators and educators to create their ADs.

In conclusion, five different profiles were identified: in-house museum educator-guide, freelance museum educator-guide, volunteer museum educator-guide, freelance audio describer working for museums, and in-house audio describer working for (1) a company that specializes in mobile guides, tactile graphics or translation or (2) a non-profit organization that specializes in disability and accessibility. Regarding their educational and professional background, there is a variety of profiles, one of which is the graduate in Translation. Overall, the results indicate that audio describers have a formal education in one or several disciplines where text analysis, verbal communication, research and critical thinking are fundamental 
Luque, M. O. \& Soler, S. (2019). Training audio describers for art museums. Linguistica Antverpiensia, New Series: Themes in Translation Studies, 18, 166-181.

skills. In addition, a majority have received training in disability, accessibility and AD. Providers of training in $A D$ include freelance audio describers, accessible communication organizations, tactile graphics companies, mobile guide companies and higher-education institutions. Although some audio describers have professional experience in positions involving research and verbal communication, not all of them have a formal education in art history, and this training is more frequent among audio describers for ADGTs, along with experience in art education and gallery teaching. Based on these results regarding audio describers' training and professional experience, we can conclude that research, verbal communication and AD skills are frequently occurring skills among audio describers in general, along with disability and accessibility skills, while art history, art education and gallery teaching skills are more common among those who do face-to-face AD. Finally, it is worth noting that some audio describers are themselves blind.

In order to improve accessibility in art museums, the different existing profiles of audio describers identified in our study should be fostered and developed further. Some years ago, the Translation and Interpreting Department of the University of Granada, in Spain, offered us the opportunity to create an internship programme for their MA students. In the next section, we introduce our proposal for contributing to current training options for this profile.

\section{Translator meta-competence and employability in AD for art museums}

Between 2012 and 2015, the EU-funded "European Work Placement Scheme" project created a platform to foster work-placement opportunities in the field of language mediation for university graduates. An important component of this scheme is a proposal for an emergent translator competence model (Kiraly \& Hofmann, 2015, p. 67). This model, which draws on Kelly's (2007) proposal, describes translator competence as a swirling vortex containing subvortices that correspond to six translator sub-competences: intercultural, communicative, instrumental, thematic, interpersonal and organizational. At the top of the vortex is the metacompetence, which is defined as the merging of the different sub-competences into a unified translator competence and is best developed during a work placement completed during the last stage of a postgraduate programme. The swirling vortex represents the "perpetual dynamic change and growth over time" (Kiraly \& Hofmann, 2015, p. 81). Whereas the psychophysiological sub-competence in Kelly's proposal is omitted in Kiraly and Hofmann's model, we find it necessary to include it, as self-confidence, attention and memory are especially important in museum AD. In this model, the work placement is a "fractal" system made up of self-similar authentic projects (Kiraly \& Hofmann, 2015, p. 84). Owing to time constraints, in our internship each student typically completes only one project. Considering this and the limited presence of intersemiotic translation in the undergraduate and MA curricula in Translation Studies, we find it beneficial to design longer internships that allow students to complete several projects and thus facilitate the emergence of the translator meta-competence.

The emergence of the translator meta-competence can have a positive impact in graduates' employability, which is understood here as the "set of skills that enable students to become employable in today's very competitive labour market" (Rodríguez de Céspedes, Sakamoto, \& Berthaud, 2017, p. 103). In a recent study on employability for Translator and Interpreter (T\&I) graduates in Spain from employers' perspectives, the results showed that most of the 
Luque, M. O. \& Soler, S. (2019). Training audio describers for art museums. Linguistica Antverpiensia, New Series: Themes in Translation Studies, 18, 166-181.

respondents agreed about the great importance of internships in facilitating graduates' job insertion (Schnell \& Rodríguez, 2017, p. 170). It also suggested that to foster graduates' employability, disciplinary or specific competences should be emphasized in the undergraduate curriculum in T\&I. In particular, greater attention should be given to specialized translation and subject-matter specialization.

When it comes to museum $A D$ as a type of specialized translation, we disagree with this view. Museum $A D$ is a relatively new professional field that currently offers limited job opportunities and so Translation graduates interested in this career path may have to complement it with other translation types. These graduates should be aware of this field in both the Translation Studies discipline and the professional world, but including such a narrow specialization in the undergraduate curriculum could be detrimental to the development of more basic competences. For this reason, we believe that the specialization in art museum AD may be best acquired during a work placement and, based on our study, it should focus on specific competences related to intersemiotic translation, disability and accessibility, gallery teaching and art education.

\section{Description of an internship in AD for art museums}

Since 2016, Kaleidoscope has offered an internship in art museum AD intended for Translation graduates, which has been completed by six students so far. All of them had previously completed a BA in Translation Studies, but this degree did not include courses or modules on media or museum AD. Five of them were in their second and last semester of the MA in Professional Translation at the University of Granada, where the internship is a 12-credit required course. They chose Kaleidoscope among a list of organizations that collaborate with this programme. In the MA programme, they had completed one course in AD for films and museums that offers a theoretical and practical introduction to this subject. The sixth student was not enrolled in this master's programme, but was completing a 16-credit Erasmus internship. The six interns had to complete a project consisting of an audio descriptive guided tour of an art museum or exhibition for BPS people, followed by an art creation workshop. During the tours in which they participated, a selection of exhibits were audio described and visitors explored tactile images or diagrams of the exhibits following verbal instructions offered by the guides. The tactile images are designed and produced in collaboration with ONCE.

The importance of real projects in translator education has been highlighted by advocates of situated learning, which is defined as

a context-dependent approach to translator and interpreter training under which learners are exposed to real-life and/or highly simulated work environments and tasks, both inside and outside the classroom (González Davies \& Enríquez Raído, 2016, p. 1).

Situated learning theories claim that learning occurs in real or, at least, realistic contexts; that learning should be unintentional, that is, students' cognitive needs arise from the tasks proposed and not from the syllabus proposed by the instructor or institution; and that it requires social interaction (González Davies \& Enríquez Raído, 2016, p. 8). Among these theories, Kiraly's (2000) proposal emphasizes the decentralization of teaching, the intersubjective construction of knowledge and the empowerment of learners through project- 
Luque, M. O. \& Soler, S. (2019). Training audio describers for art museums. Linguistica Antverpiensia, New Series: Themes in Translation Studies, 18, 166-181.

based methods. Kiraly's (2012) holistic-experiential approach to translator training is the refinement of his original authentic project-based proposal for translator education (Kiraly, 2000). While the latter is based on social-constructivist learning theories, the holisticexperiential approach incorporates enactivist theories of cognitive biology, where the human mind is described as autopoietic (self-creating and self-regulating) and learning is conceived of as a "perpetual act of becoming" that is "deeply rooted in authentic, embodied action" (Kiraly, 2012, pp. 90-91).

In the next section, the project completed by interns at Kaleidoscope is described in connection with Kiraly's proposals. This description is supported by excerpts from the interns' assessment of the internship included in the internship report they completed for the MA programme, their MA final project and their comments during the assessment meetings with the internship mentor.

\subsection{Overall organization of the internship}

Interns complete a collaborative, authentic translation project, defined by Kiraly (2012) as "a holistic piece of work undertaken by a team of students in the service of a real-world client or user" (p. 84) and "a scaffolded opportunity for multi-facetted (and co-emergent) experiential learning" (p. 91). We adopt an approach where learning through collaborative action by carrying out real-world tasks in a non-teacher-centred environment empowers learners to construct their professional self-esteem or self-concept (Kiraly, 2000, p. 19). Instructors are not just "facilitators" who serve as a connection between the real world and the learners, that is, mentors do not work only as reviewers of the interns' work; they also help them to focus on their relationship with users. They are equals in the project in that they are part of a mutually constructive process in which both learners and instructors "appropriate" knowledge, that is, they "internalize socio-cultural knowledge" in a process in which interpersonal knowledge is transformed into intra-personal knowledge through dialogue and discussion (Kiraly, 2000, pp. 38-39). With this process, several phases of dialogue and internalization are achieved: dialogues are constructed through several varied prisms based on the voices of the associations, the museum, the mentors and the interns. Nevertheless, "scaffolding" - understood as the instructor's guidance and support for learners to solve problems and develop their skills (Kiraly, 2000, p. 45) - is highly important owing to the limited experience of interns in this type of project. The project organization is based on the method developed by Kaleidoscope to design and implement audio descriptive guided tours, which is informed by our descriptive and applied research in art museum AD (Soler Gallego, 2018; Soler Gallego, Luque Colmenero, \& Rodríguez Posadas, 2016). Our educational approach is therefore "transformationist", that is, it creates "a student- and learning-centred context that focuses on collaborative study and exploration of the translation process with the teacher acting as a guide" (González Davies \& Enríquez Raído, 2016, p. 7) and internship mentors are responsible for the general organization of the project and the last revision of the product.

Interns are assumed to have acquired the intercultural, communicative, instrumental, thematic, interpersonal, organizational and psychophysiological competences or skills (Kelly, 2007) for interlingual translation during their BA. In addition, they have started to acquire disability, accessibility and AD skills during their MA studies at the University of Granada. Thus, the goal of the internship is for students to develop these competences further and start 
Luque, M. O. \& Soler, S. (2019). Training audio describers for art museums. Linguistica Antverpiensia, New Series: Themes in Translation Studies, 18, 166-181.

acquiring art-education and gallery teaching skills and to help their translator metacompetence to emerge. To achieve this goal, we designed a project-based internship consisting of three chronological stages over a period of three months: introduction, project and assessment (Table 2). Each stage comprises learning activities and assessment components designed to achieve the following learning outcomes.

Upon completion of the internship, students will be able to:

1. Explain and comment on the fundamental concepts of disability and accessibility, current accessibility practices in art museums and exhibitions, and the main research in this field.

2. Design and organize audio descriptive guided tours in art museums and exhibitions, including the required communication with visitors and the museum staff.

3. Create scripts for ADGTs that include:

a. written descriptions of artwork, following various approaches based on existing practices and research in the field, and

b. verbal instructions to guide the exploration of tactile resources of various kinds.

4. Guide audio descriptive guided tours in art museums and exhibitions following an approach based on participatory gallery teaching and experience-based art education.

Table 2 Internship organization.

\begin{tabular}{|l|l|}
\hline Stage 1: Introduction & $\begin{array}{l}1.1 \text { Survey of intern's experience and expectations } \\
1.2 \text { Discussion of recommended bibliography } \\
1.3 \text { Discussion of previous projects }\end{array}$ \\
\hline 2.1 Meetings \\
a) Approach meeting \\
b) Meeting with museum staff \\
c) Meeting with consultants \\
d) Project specific meeting \\
i. Selection of works \\
ii. Selection of materials \\
iii. Selection of activities \\
2.2 Individual translation \\
a) Documentation \\
b) Script composition \\
c) Self-revision \\
2.3 Revision in teams \\
a) Peer revision \\
b) Revision by mentor \\
c) Revision by curators \\
d) Revision by BPS consultants \\
e) Revision by mentor \\
2.4 Tour rehearsal \\
2.5 Audio descriptive guided tours \\
2.6 Project assessment \\
a) External
\end{tabular}


Luque, M. O. \& Soler, S. (2019). Training audio describers for art museums. Linguistica Antverpiensia, New Series: Themes in Translation Studies, 18, 166-181.

\begin{tabular}{|l|l|}
\hline & \multicolumn{1}{|c|}{$\begin{array}{l}\text { i. Museum } \\
\text { ii. Associations and visitors } \\
\text { b) Internal: Mentors and interns }\end{array}$} \\
\hline Stage 3: Intern assessment & $\begin{array}{l}\text { 3.1 Assessment by mentors } \\
\text { 3.2 Self-assessment }\end{array}$ \\
\hline
\end{tabular}

\subsection{Stages 1 and 2: Introduction and project development}

The introduction phase consists of meetings at which the internship mentors survey interns' experience and expectations. The interns are also provided with reading materials on current research, guidelines and practices in museum AD (such as Reich et al., 2011; Salzhauer Axel, Hooper, Kardoulias, Stephenson Keyes, \& Rosenberg, 2003; Soler Gallego, 2012). These materials are explained and critically discussed by the interns, and are used as reference materials throughout the internship. Finally, previous projects carried out by Kaleidoscope are presented and discussed to give the interns an overview of the tasks they will carry out. These activities help to achieve the first of the learning outcomes of the programme.

The next and main stage is project development. The project development phase starts with several meetings of the mentors and the interns, both face-to-face and online. After these initial meetings and during the preparation of the tours (individual work and revision stages) further meetings are held, mainly at the museum or exhibition. Following Kiraly's enactivist approach to curriculum design for translator training, the interns play an active role in the initiation and development of the project (Kiraly, 2012, p. 91). This is reflected in the following comment by one of them:

At first, I was struck by the fact that our word had the same weight as the mentor's word. We were all equal and all ideas were well received [our translation].

The first of these meetings is the so-called "approach meeting", at which the general approach we are going to take in each individual project is discussed based on the analysis of the translation brief and the documentation provided by the museum. This meeting also helps to create a team identity for the following meetings with the museum staff and the BPS consultants.

The project-specific meeting is held once the general approach has been discussed with the museum staff and the BPS consultants, and it consists of three parts: selection of works, selection of multisensory materials for the visit and selection of the activities for the art creation workshop. A report of this meeting is shared with the client, namely the museum or the exhibition curators and educators, for them to revise it. After that revision, the interns receive feedback and amend the text, where necessary. This feedback, together with that of the users, is highly important for the training, because it gives them a real scenario of their achievements for the second learning outcome of the programme. Also, during the specific meeting the interns choose the works they are going to audio describe and the other components of the guided tour and the workshop that they would like to be responsible for, such as the contact with collaborators, the selection of tactile materials and the preparation of these materials. All the interns complete one full project, but since the association typically carries out several projects simultaneously, the interns also participate in some stages of other 
Luque, M. O. \& Soler, S. (2019). Training audio describers for art museums. Linguistica Antverpiensia, New Series: Themes in Translation Studies, 18, 166-181.

projects. This gives them an opportunity to practise with different components of the tour and types of visual art $A D$ related to the medium (painting, drawing, engraving, sculpture) and style (from representation to abstraction).

To date, interns at Kaleidoscope have designed and implemented audio descriptive guided tours for the Museo CajaGranada, the Fundación Rodríguez Acosta and two temporary art exhibitions at the Alhambra in Granada and the Museo de Arte Naïf in Jaén. In addition, two interns helped to create the script of an audio descriptive guide for the Cueva de las Ventanas archaeological site, which will also be used to guide audio descriptive tours. In these projects, as in previous ones, we collaborated with ONCE.

In the following stage, the interns work individually to compose the script for the guided tour, which consists of the following sections or discourse moves (Soler Gallego, 2016): (1) introduction to the tour and the museum or the exhibition; (2) contextual information; (3) audio description; (4) discussion with visitors, and (5) verbal instructions to explore the tactile image. Moves 2 to 5 are repeated for each work selected for the tour. This process, as with any translation process, consists of documentation, script composition and self-revision tasks. Subsequently, the individual work is revised in a circular and collaborative way, both by the other interns and their mentors and by the curators and BPS consultants.

An essential aspect of the methodology followed by Kaleidoscope is the participation of BPS people in the process, as defended by the emancipatory disability research approach (Hollins, 2010). This theory-methodology emphasizes the active participation of beneficiaries in research processes on disability and highlights the value of their expert opinion. Two rounds of revisions are completed, starting with the intern's peers, followed by that of their mentors, and ending with the consultants and the curators. The script is then revised a second time by the mentors before a final revision is carried out by both interns and mentors during a rehearsal of the guided tour at the museum or the exhibition. Finally, the interns guide audio descriptive tours for BPS visitors. With this procedure, the interns are capable of achieving all four learning outcomes, from understanding the current accessibility practices, needs and developments in this field of $A D$ to designing and conducting tours and structuring the phases of a project, based on this understanding and their total and full experiences from top to bottom.

In the audio descriptive guided tours given by Kaleidoscope the museum is conceived as a space of transformation and therapeutic utility and the museum and its collection are tools that give value to people with disabilities (García Sandoval, 2015, p. 36). We try to foster "an exchange with no predefined hierarchies, within which all partners are equally entitled to express themselves, bear responsibility collectively and listen to one another" (Pro Helvetia, p. 101),

following the principles of cultural mediation of the arts:

... médiation culturelle is understood less as knowledge transmission and more as the act of forming relationships of mutual exchange among publics, works, artists and institutions. Under this understanding, the aim of médiation culturelle is to place the various different perspectives involved in relation to one another. These activities focus on the individual perception of artworks by participants... Ideally, the collective analysis of the different forms of expression 
Luque, M. O. \& Soler, S. (2019). Training audio describers for art museums. Linguistica Antverpiensia, New Series: Themes in Translation Studies, 18, 166-181.

which are brought together in this process of exchange is another integral part of médiation culturelle de l'art (Pro Helvetia, p. 18).

One specific strategy that we implement in this approach is an adaptation of Visual Thinking Strategies, a method of engaging learners of art in deep experiences of looking at art and discussing meanings with peers by asking them three specific questions about their perceptions and interpretations of the work (Hailey, Miller, \& Yenawine, 2015, p. 52). In our tours, after audio describing the work, we invite BPS visitors to share their impressions. This method allows visitors to understand that their experiences and knowledge are valued and that their needs regarding access to visual art and museums are acknowledged. Along these lines, in the project that took place in the Alhambra of Granada, the interns suggested that the historical information be presented in a discussion format, asking visitors the six questions, who, when, where, why, how and what. This proposal demonstrated the empowerment of the interns and contributed to emphasizing the participatory and emancipatory features in our approach.

With the help of these dialogical strategies, the idea appears of translators emerging along with their fellow learners, mentors, institutions and the community of translation practice instead of being trained; learners do not find themselves placed in a static situation but rather are part of the situation itself (Kiraly, 2012, pp. 87-89). According to Kiraly (2000), "the interchange between multiple realities in a social environment naturally leads to debate, negotiation and thus to change and growth in each individual perspective" (p. 34). The concept of "multiple realities" seems to expand when the disability-accessibility component comes into play in a translation project. Perspectives multiply, thanks to a variety of individuals who participate in the project: interns' peers and mentors; museum educators, curators, BPS consultants, ONCE staff and BPS visitors; in addition, there are the relatives, friends and caretakers who accompany them during the visit. This multiplicity of connected realities and the variety of tasks accomplished by the interns (audio describing, being sighted guides, guiding tactile explorations, selecting and creating multisensory materials, including tactile images, and designing and guiding art creation workshops) is an excellent example of the complexity of the translation process and translator education from a post-positivist perspective. Finally, after all the programmed tours have taken place, the project is assessed by the client and the visitors via interviews and questionnaires, and also by the Kaleidoscope team during a final meeting.

\subsection{Stage 3: Intern assessment}

The interns' learning is assessed both by the internship mentors and by the interns themselves, which allows them to learn directly from the assessment process itself (Birkan Baydan \& Banu Karadağ, 2014, p. 987). The assessment is both formative and summative. The formative assessment consists of the mentors' final revision of the translations produced by the interns during the second stage of the internship, before the rehearsal of a guided tour starts. It also includes discussions of the interns' perceived learning during the meetings held throughout the internship period. In addition to this formative self-assessment throughout the project, some interns complete a summative self-assessment at the end. Those enrolled in the MA programme at the University of Granada complete an internship report and can choose to write a final MA project consisting of a critical discussion of the project completed 
Luque, M. O. \& Soler, S. (2019). Training audio describers for art museums. Linguistica Antverpiensia, New Series: Themes in Translation Studies, 18, 166-181.

for the internship and its connection with translator competence. Finally, the mentors complete a summative assessment of the interns' learning process, based on their performance and progress during the programme, including the guided tours.

Based on the interns' assessment, we can conclude that the translator sub-competences are highly interwoven in the internship described. In her internship report, one intern affirmed that all her translator sub-competences were improved throughout the internship period. She decided to draw on Kelly's (2007) model, which she knew from her T\&l studies. She indicated that these sub-competences included the communicative and textual sub-competence (translating images into words), the cultural and interpersonal sub-competences (translating face-to-face for people with a disability and being sighted guides), the thematic subcompetence (discussing accessibility and art history), the instrumental sub-competence (using documentation tools to research specific topics) and the psychophysiological sub-competence (memorizing the scripts). She also stated that all these were harmonized and made her strategic competence, understood as the capability to face any situation and seek solutions, arise. Her analysis illustrates how translator competence emerges in a "self-regulating" process supported by tasks and projects, material and human resources, personal and interpersonal dispositions, and ideational, cultural and linguistic resources (Kiraly \& Hofmann, 2015, p. 82).

Regarding the psychophysiological sub-competence, this emergent and emancipatory way of learning seems to lead to a sense of belonging and, thus, to a sense of responsibility and determination. One intern stated:

I have always felt like a real member of Kaleidoscope. Although our mentor made the more important decisions (with our advice), she has always given us a voice both in the process of designing and organizing the tours and in their development [our translation from Spanish].

This is related to the transformationist approach to teaching adopted for the internship, which moves from instructor-controlled to learner-controlled sessions (González Davies \& Enríquez Raído, 2016, p. 7).

With a view to a professional future, one intern stated that the internship favoured the development of important skills, such as the ability to analyse multiple situations quickly and seek an effective and immediate strategy, for example, for adapting the script during the tour based on a visitor's needs. According to her, her awareness of the importance of teamwork also increased during the internship. She reckoned that this knowledge would help her work more effectively in a team at some point in her career. This suggests that internship experience helps interns to develop their teamwork skills not only during the internship, but also during their future development as professional translators. These reflections connect with the non-linear view of translator education advanced by Kiraly $(2012$, p. 84), where a mixture of advanced and basic tasks are interconnected throughout the training period. This prepares learners for "the infinitely variable new constellations of words, concepts, messages, authors, clients, translation briefs, collaborators, resources, readers and of course the myriad of translator-specific factors" that professional translators face nowadays (Kiraly, 2012, p. 87).

Finally, this emancipatory training, where the main goal is the learner's empowerment (Kiraly \& Hofmann, 2015, p. 82), leads to deep and mature reflections on the part of the interns 
Luque, M. O. \& Soler, S. (2019). Training audio describers for art museums. Linguistica Antverpiensia, New Series: Themes in Translation Studies, 18, 166-181.

regarding the translator profession. According to the self-assessment of one of them, she felt fully capable of facing the labour market, since the training had not only made her grow as a translator and helped her in the process of professionalization, but had also made her grow and mature as a person by enabling her to adapt to adverse circumstances when there is no manual. She continued:

In the times we live, a lot of emphasis is placed on people's degrees. The eagerness for diplomas and titles is abused, which seems to be everything for the potential entrepreneurs who are going to hire us and we stop paying attention to other virtues, equally necessary, such as empathy with the rest of the people, specifically with people who do not have the same possibilities we have [our translation from Spanish].

\section{Conclusions}

Our study of the profile of the audio describer for art museums has shown that people who are responsible for making works of art in museums accessible to BPS people have various professional and educational backgrounds. We hope that this study will increase museum and $A D$ professionals' awareness of these different profiles, which could lead to the emergence of even more creative and enriching practices in this field. If accessibility is to be improved at museums, these institutions should benefit from working with individuals with different backgrounds and approaches to visual art AD.

One of the profiles identified in our study is that of the Translation graduate. The internship programme developed by Kaleidoscope and described in this article has proved to help acquire the set of competences proposed in this programme for the audio describer for art museums. Even though acquiring various multidisciplinary competences is important for this type of translation, the most important factor that internship programmes in this area should take into account is practice in real-life situations that involves a close collaboration with BPS people and museums right from the beginning of the programme.

At a time when more and more voices are criticizing the emphasis placed on employability and the increasingly vocational approach in higher-education institutions, we agree that collaboration between these institutions and employers at different levels of the curriculum, inclusive of internships, can help to establish a balance between disciplinary knowledge and professional knowledge (Schnell \& Rodríguez, 2017, p. 180). But we also conclude that this collaboration will be beneficial only as long as all the parties involved - translation professionals and universities, museum professionals and BPS people - participate in the discussion, the training and the emancipation of the students and interns.

\section{References}

Atlas.ti (Version 8) [Computer software]. Scientific Software Development.

ADLAB PRO. (2017). Audio description professional: Profile definition. Retrieved from http://www. adlabpro.eu/wp-content/uploads/2017/12/20170608_uam_io1_report.pdf

Birkan Baydan, E., \& Banu Karadağ, A. (2014). Literary translation workshop: Social constructivist approach classroom activities. Procedia - Social and Behavioral Sciences, 152, 984-988.

Díaz Cintas, J. (2007). Por una preparación de calidad en accesibilidad audiovisual. TRANS, 11, 45-59. 
Luque, M. O. \& Soler, S. (2019). Training audio describers for art museums. Linguistica Antverpiensia, New Series: Themes in Translation Studies, 18, 166-181.

García Sandoval, J. (2015). Museum, arts and health - as encounter and inclusive culture: Relationships, experiences and best practices in Spanish museums. Her\&Mus: Heritage \& Museography, 16(7:1), 33-46.

González Davies, M. \& Enríquez Raído, V. (2016). Situated learning in translator and interpreter training: Bridging research and good practice. The Interpreter and Translator Trainer, 10(1), 111.

Hailey, D., Miller, A., \& Yenawine, P. (2015). Understanding visual literacy: The Visual Thinking Strategies approach. In D. M. Baylen \& A. D'Alba (Eds.), Essentials of teaching and integrating visual and media literacy (pp. 49-73). New York, NY: Springer.

Hollins, H. (2010). Reciprocity, accountability, empowerment: Emancipatory principles and practices in the museum. In R. Sandell, J. Dodd, \& R. Garland-Thomson (Eds.), Re-presenting disability: Activism and agency in the museum (pp. 228-243). London: Routledge.

Kelly, D. (2007). Translator competence contextualized. Translator training in the framework of Higher Education reform: In search of alignment in curricular design. In D. Kenny \& R. Kyongjoo (Eds.), Across boundaries: International perspectives on Translation Studies (pp. 128-142). Newcastle: Cambridge Scholars.

Kiraly, D. (2000). A social constructivist approach to translator education: Empowerment from theory to practice. Manchester: St. Jerome.

Kiraly, D. (2012). Growing a project-based translation pedagogy: A fractal perspective. Meta, 57(1), 8295.

Kiraly, D., \& Hofmann, S. (2015). Towards a postpositivist curriculum development model for translator education. In D. Kiraly (Ed.), Towards authentic experiential learning in translator education (pp. 67-87). Mainz: V\&R.

Orero Clavero, P. (2005). Audio description: Professional recognition, practice and standards in Spain. Translation Watch Quarterly, 1, 7-18.

Pro Helvetia. (n.d.). Time for cultural mediation. Retrieved from https://prohelvetia.ch/app/uploads/ 2017/09/tfcm_0_complete_publication.pdf

Reich, C., Lindgren Streicher, A., Beyer, M., Levent, N., Pursley, J., \& Mesiti, L. A. (2011). Speaking out on art and museums: $A$ study on the needs and preferences of adults who are blind or have low vision. Museum of Science Boston and Art Beyond Sight.

Rodríguez de Céspedes, B., Sakamoto, A. , \& Berthaud, S. (2017). Introduction. The Interpreter and Translator Trainer, 11(2-3), 103-106.

Saldanha, G., \& O'Brien , S. (2013). Research methodologies in Translation Studies. London: Routledge.

Salzhauer Axel, E., Hooper, E. V., Kardoulias, T., Stephenson Keyes, S., \& Rosenberg, F. (2003). AEB's guidelines for verbal description. In E. Salzhauer Axel \& N. Sobol Levent (Eds.), Art beyond sight: A resource guide to art, creativity, and visual impairment (pp. 229-237). New York, NY: AFB.

Schnell, B., \& Rodríguez, N. (2017). Ivory tower vs. workplace reality. Employability and the T\&I curriculum - balancing academic education and vocational requirements: A study from the employers' perspective. The Interpreter and Translator Trainer, 11(2-3), 160-186.

Soler Gallego, S. (2012). Traducción y accesibilidad en el museo del siglo XXI. Granada: Ediciones Tragacanto.

Soler Gallego, S. (2016). A corpus-based genre analysis of art museum audio descriptive guides. In F. Alonso Almeida, L. Cruz García, \& V. González Ruiz (Eds.), Corpus-based studies on language varieties: Linguistic insights (pp. 145-166). Bern: Peter Lang.

Soler Gallego, S. (2018). Audio descriptive guides in art museums: A corpus-based semantic analysis. Translation and Interpreting Studies, 13(2), 230-249.

Soler Gallego, S., \& Luque Colmenero, M. O. (2018). Paintings to my ears: A method to study subjectivity in audio description for art museums. Linguistica Antverpiensia New Series - Themes in Translation Studies, 17, 140-156.

Soler Gallego, S., Luque Colmenero, M.-O., \& Rodríguez Posadas, G. (2016). Words to see: On the intersemiotic translation of composition in paintings. In A. Rojo López \& N. Campos Plaza (Eds.), 
Luque, M. O. \& Soler, S. (2019). Training audio describers for art museums. Linguistica Antverpiensia, New Series: Themes in Translation Studies, 18, 166-181.

Interdisciplinarity in translation studies: Theoretical models, creative approaches and applied methods (pp. 277-294). Bern: Peter Lang. 